\title{
Análise Comportamental do Discurso: Fundamentos e Método ${ }^{1}$
}

\author{
Elizeu Borloti ${ }^{2}$ \\ Alexandra Iglesias \\ Camila Mattedi Dalvi \\ Renata Danielle Moreira Silva \\ Universidade Federal do Espírito Santo
}

\begin{abstract}
RESUMO - Este estudo descreve uma Análise Comportamental do Discurso (ACD), apresenta seus fundamentos e um método para efetivá-la, inferido de O Comportamento Verbal, de Skinner. Propõe a tese de que a ACD possa ser uma vertente de Análise do Discurso (AD), devido aos seus fundamentos epistemológicos: anti-mentalismo, anti-realismo e contextualismo. Discurso é um conjunto de comportamentos verbais sob controle das contingências de reforço (históricas e atuais) cujo sentido advém desse controle. Ao construir seu discurso, o falante combina operantes essenciais (mandos e tatos) em grupos temáticos intraverbais (emitidos às vezes como se fossem tatos) que são modificados com autoclíticos apropriados.
\end{abstract}

Palavras-chave: análise do discurso; comportamento verbal; psicologia social comportamental.

\section{Behavioral Analysis of Discourse: Basis and Method}

\begin{abstract}
This study describes a Behavioral Analysis of Discourse (BAD). It presents the basis of BAD, describing a method to effect it, inferred from Skinner's Verbal Behavior. It proposes that BAD could be a modality of Discourse Analysis (DA) due to its epistemological basis: anti-mentalism, anti-realism and contextualism. Discourse is a set of verbal behaviors under the historical control and current contingencies of reinforcement, whose sense come upon that control. In the point of constructing his/her discourse, the speaker combines essential operants (commands and tacts) in intraverbal thematic groups (sometimes emitted as if they are tacts) that are modified with appropriated autoclitics.
\end{abstract}

Key words: discourse analysis; verbal behavior; behavioral social psychology.

Que há num simples nome? O que chamamos rosa, com outro nome não teria igual perfume?

(Shakespeare, em Romeu e Julieta, 1594-1595, Ato II - Cena II)

Diferentes movimentos teórico-metodológicos modificaram o foco de interesse das pesquisas na Psicologia Social. Algumas historiografias dessa área (Banchs, 1988; Lane, 1995; Spink \& Frezza, 1999) descrevem o impacto desses movimentos nos alvos de investigação dos psicólogos sociais: "percepção", "atitudes”, "crenças”, "cognição", "representação social", "construções sociais" e, mais recentemente, "discursos". Seja como for, o "dado" da pesquisa psicossocial tem sido basicamente o que as pessoas dizem acerca da realidade social e isso demonstra o importante papel do comportamento verbal no estudo dos processos psicossociais.

Teun van Dijk (2004) especifica as origens de parte dessas transformações, apontando, nas Ciências Sociais, um crescente interesse no estudo do "uso da linguagem" em conversas. Esse movimento - que ele chamou de "giro discursivo" - vem

1 Trabalho originalmente apresentado no XIV Encontro da Associação Brasileira de Psicoterapia e Medicina Comportamental, realizado de 25 a 28 de agosto de 2005, em Campinas, SP. O método descrito aqui foi derivado de uma pesquisa de doutoramento do autor principal (com o apoio financeiro da CAPES) e aperfeiçoado em um projeto de pesquisa empírica do PIBIC-UFES, com a participação das co-autoras, alunas da graduação, com dados em publicação.

2 Endereço: Avenida Copacabana, 569-68, Morada de Laranjeiras, Serra, ES, Brasil 29166-820.E-mail: borloti@hotmail.com substituindo a abordagem formal e abstrata da gramática de uma língua pelo "estudo do discurso". A concepção básica dos integrantes desse movimento pode ser assim sintetizada: 1) o conhecimento que as pessoas têm está em seus discursos; e esse conhecimento é compartilhado socialmente entre comunidades; 2) discursos não podem ser isolados do "uso da linguagem", pois "a linguagem, o discurso e o conhecimento são essencialmente sociais" (Dijk, 2004, p. 9).

Foi essa concepção básica que deu origem à Psicologia Social do Discurso que, segundo Dijk (2004), adota uma postura anti-experimentalista (simplesmente por priorizar o estudo da conversação natural - ou transcrições de conversações naturais, ao invés de situações experimentais artificiais), anti-mentalista (ao estudar o "uso verdadeiro de termos psicológicos"), anti-realista e, diz ele, anti-empirista (ao estudar "construções sociais" e não o "real"): (...) a realidade para as pessoas é aquilo que as pessoas constroem como sendo real (Dijk, 2004, p. 11).

Em termos gerais, os psicólogos sociais do discurso se opõem à concepção tradicional de linguagem como algo que expressa o "mundo das idéias", tal como um "instrumento do pensamento" ou "representação". Ao contrário, eles a compreendem como uma ação "para fazer coisas" (Gracia, 2004, p. 47). Nisso, eles comungam com as idéias da Pragmática Moderna ao afirmarem que os sentidos da fala não estão nos signos lingüísticos, mas sim na própria interação. Como tal, o discurso é um tipo de prática social. Por essa razão, mas não somente, os procedimentos da análise do discurso (AD) analisam aquilo que se entende por um "conjunto de 
enunciados produzidos em contextos sociais a partir de posições de enunciação" (Iñiguez, 2004c, p. 155). A ênfase no dado verbal vocal é tanta que as entrevistas transcritas têm sido amplamente usadas em pesquisas qualitativas (Bauer \& Gaskell, 2000/2002; Rocha-Coutinho, 1998).

Poter, Wetherell, Gill e Edwards (1990, p. 206) lembraram que há pelo menos quatro tipos de "AD". Um tipo com maior orientação psicológica e vínculos fortes no cognitivismo preocupa-se com "o modo como o padrão do discurso afeta a lembrança e a compreensão dos eventos". Um outro tipo, influenciado pela "teoria dos atos de fala", tem por objetivo "prover um relato sistemático da organização da interação verbal" entre os falantes. Um terceiro tipo está embasado na análise foucaultiana das práticas sócio-culturais. Um quarto tem raízes na Sociologia da Ciência. Esses usos do termo "AD" mostram graus variados de especificidade e uma sutil modulação teórica. Como resultado, há uma forte discordância entre os analistas de discurso sobre o que eles estão estudando e como deveriam estudá-lo, já que os termos "análise" e "discurso" podem significar coisas diversas. Parker (1999) tentou resolver o impasse, dizendo que os analistas de discurso estudam o modo como os conjuntos de enunciados são construídos, como as funções da linguagem operam e as contradições que surgem durante esse funcionamento.

Claro está que certa noção de "função" é importante na AD. Para os analistas do discurso, o discurso não é um acesso às representações sociais (ou mentais) dos falantes ou ao conteúdo (a ser analisado) de suas falas. Ao invés disso, o discurso, segundo eles, funcionaria para "sempre fazer coisas". Ao "construir" (descrever) realidades, o falante afeta o ouvinte, seja legitimando ou desafiando, suportando ou ironizando, endossando ou subvertendo o que diz (Parker, 1992).

É curioso pensar que a noção de "função" do discurso, conforme apontada por Parker (1999), tem algo a ver com a noção de função na análise funcional do comportamento verbal (Skinner, 1957), já que "coisas feitas" pode ser entendido como conseqüências sobre um ouvinte. A despeito disso, é comum encontrar nos textos dos pioneiros da análise do discurso menção a uma oposição ao behaviorismo radical de B. F. Skinner (Iñiguez, 2004a). Entretanto, vale lembrar que o behaviorismo radical é anti-mentalista, anti-realista, contextualista e construcionista (Baum, 1994/1999; Kohlenberg \& Tsai, 1991/2001; Vargas, 1992). Portanto, não seria sem propósito responder ao seguinte questionamento: a teoria contextual do significado do comportamento verbal de Skinner (1957) seria útil na análise do discurso?

Alguns pesquisadores ajudaram a edificar aquilo que chamamos neste artigo de Análise Comportamental do Discurso (ACD). Sá (1983), por exemplo, comparou a noção de "controle" na obra de Skinner com a noção de "poder" na obra de Foucault. Pereira (2000) fez o mesmo com a noção de "posicionamento" da lingüística de Bakhtin e a de "operante" da proposição de Skinner. "Crenças", "atitudes" ou "conhecimento social" também foram analisados como comportamentos verbais (Borloti \& Trindade, 2000; Guerin, 1992, 1994) e "ideologia" foi reconceituada pelas relações verbais que a definem (Borloti, 2004a). A falta de delimitação dos conceitos de "prática cultural" e de "comportamento social", nos textos dos psicólogos sociais, também foi criticada por analistas de comportamento, que propuseram definições operacionais desses (Guerin, 1994; Lamal, 1991). Igualmente, conceitos vagos usados por lógicos, tais como "argumentos", "raciocínio dedutivo/indutivo" ou "poder de convencimento", foram analisados funcionalmente (Terrell \& Johnston, 1989). Lingüistas também reconheceram a influência do behaviorismo em seu campo de estudos. Uma historiadora dessa disciplina (Andresen, 1990) apontou que a abordagem de Skinner foi precursora da Pragmática, um dos fundamentos do trabalho dos analistas do discurso na atualidade (Iñiguez, 2004b).

Entretanto, a análise do comportamento verbal não é posta como possibilidade de compreensão dos discursos, seja devido à análise anacrônica do behaviorismo no discurso dos psicólogos sociais (aquilo que Sá, 1994, chamou de “o fantasma do behaviorismo"); seja devido ao desconhecimento de um procedimento comportamental de AD. Portanto, tornase relevante apontar essa possibilidade.

Ao se considerar todos esses aspectos, este artigo, então, tem os seguintes objetivos: 1) discutir os fundamentos de uma Análise Comportamental do Discurso (ACD) e 2) apresentar um método para conduzir essa análise. $\mathrm{O}$ artigo começa apresentando a análise do discurso (AD) para que se possa compreender a formulação da ACD, a partir do que foi enunciado no livro O Comportamento Verbal (Skinner, 1957).

\section{Definindo AD e descrevendo como ela é feita}

A AD teve origem na Lingüística e, muito sinteticamente, pode ser definida como a análise da "linguagem em seu uso", indo além da oração, frase ou conteúdo (de fato, analistas do discurso dizem que fazem algo muito diferente da "análise de conteúdo", conforme descrita por Bardin, 1979). Entretanto, definir $\mathrm{AD}$ a partir das conceituações de discurso nem sempre ajuda.

Iñiguez (2004b) mostrou as concepções mais comuns de discurso cujos termos gerais podem ser mesclados assim: discurso é um conjunto de enunciados de um falante num contexto de interação (e com poder de ação e de normatização e, portanto, com uma ideologia específica), constituindo um objeto produzido e produtor de certas relações sociais. Diante da diversidade de opiniões, o autor optou pela seguinte definição de $\mathrm{AD}$ : "um discurso é um conjunto de práticas lingüísticas que mantêm e promovem certas relações sociais" (Iñiguez \& Antaki, 1994, p. 63).

Para proceder à análise, os analistas do discurso (Gill, 2000/2002) destacam o que chamam de: 1) "texto-discurso": enunciados (ou conjunto de) produzidos em certos contextos específicos e, portanto, reveladores de condições históricosociais que lhes dão força; 2) "enunciador": o "autor" do texto-discurso; 3 ) "corpus" do discurso: sua "materialização" em conversas e entrevistas transcritas, livros e artigos publicados, documentos oficiais, palestras gravadas, etc. Destacados esses elementos, a AD se inicia, primeiro, perguntando-se sobre quais são as relações sociais entre falantes e ouvintes das quais faz parte o discurso que se vai analisar.

Depois, é preciso selecionar o material relevante para a análise. Qualquer que seja a escolha, é importante lembrar que o "texto-discurso" deve conter propriedades das quais são inferidos "efeitos discursivos", ou seja, efeitos que operam num "nível superior" ao do falante e/ou ouvinte, apontando para "sentidos", "ordens do mundo", "olhares". Não se sabe 
bem por que os analistas do discurso enfatizam que "efeitos" não são "conseqüências", entretanto essa afirmação aparece contradita de algum modo em seus enunciados:

Ao ler os textos, devemos buscar os efeitos que o material gera por si mesmo, que não é outro senão aquele que o/a leitor/a

é capaz de captar. $O$ trabalho analítico consiste em examinar cuidadosamente os textos, buscando todas as possíveis leituras, e identificar os efeitos mais conectados com a relação social que queremos elucidar (Iñiguez, 2004c, p. 139).

Por último, procede-se à análise propriamente dita. Um primeiro passo é a preparação do corpus em um formato manipulável (arquivo informatizado, por exemplo), em uma transcrição o mais detalhada possível (Iñiguez, 2004c). Após a preparação adequada, usam-se os procedimentos analíticos da AD, advindos de diferentes vertentes. A vertente da Teoria dos Atos de Fala (Austin, 1998; Searle, 1965) foca o que fazem os enunciados: suplicam, sancionam, prometem, etc. A vertente da Pragmática (Levinson, 1983) busca o sentido na informação contextual, que se mostra apesar da polissemia da palavra. Por sua vez, a perspectiva da Retórica (Billig, 1987; Perelman, 1993) foca práticas argumentativas, táticas estilísticas, estratégias de convencimento, de persuasão e coisas desse tipo.

Defende-se aqui que uma Análise Comportamental do Discurso (ACD) poderia ser mais uma vertente possível de AD por combinar os objetivos de análise das principais vertentes sintetizadas acima e, como se verá a seguir, por comungar das principais bases epistemológicas da AD. Como dito antes acerca da postura da Psicologia Social do Discurso, essa comunhão permanece mesmo após considerações críticas à sinonimia que os analistas do discurso estabelecem entre "experimental" e "artificial" e "empírico" e "real".

\section{Fundamentos de uma ACD}

O discurso skinneriano acerca do comportamento verbal foi enunciado na década de 1930 e modificado ao longo dos vários anos seguintes até a sua publicação no final da década de 1950 (Borloti, 2003). Já na década de 1930, quando abordagens no campo de estudos da linguagem e da fala divergiam, Skinner (1957) enunciou um novo objeto de estudo: um comportamento que, ao contrário do comportamento não-verbal, só consegue modificar o ambiente físico pela mediação de outras pessoas, já que seu primeiro efeito é sobre outro repertório, que pode incluir o do próprio falante . $^{3}$

Como um estrategista, Skinner não quis usar o termo "fala", pois descreve o comportamento verbal vocal (portanto, exclui os gestos como verbais, conforme defesa de McNeill, 1985, e do próprio Skinner, 1986); não quis "linguagem", pois descreve as práticas de uma comunidade lingüística (portanto, focaliza a língua e suas regras; não o comportamento que a produz). Preferiu o termo "comportamento verbal" para destacar um comportamento modelado e mantido por

3 Os termos "falante" e "ouvinte" serão usados neste artigo de forma genérica para designar um repertório verbalizador e um conseqüenciador, respectivamente. Ambos podem ser partes do repertório de uma única pessoa. Embora Vargas (1991), visando evitar problemas de localização, tenha sugerido os termos verbalizador e conseqüenciador, para falante e ouvinte, respectivamente, preferiu-se manter os termos originais de Skinner. conseqüências mediadas no contexto social, emitido em qualquer modalidade verbal (Catania, 1998): falada, escrita ou gestualizada, citando as mais comuns. É por tal preferência que a retórica de Skinner (Woodward, 1996) acerca do comportamento verbal se contrapôs ao que ele chamou de "formulações tradicionais" no campo da Lingüística, do Criticismo Literário e da Filosofia e Psicologia da Linguagem, caracterizadas, nos anos 1930, por uma postura estruturalista, mentalista, realista e/ou representacionista.

Skinner estava interessado em uma análise da função do comportamento verbal operante e não das formas lingüísticas (Richelle, 1976). Como operante, o verbal estabelece uma relação contextual e indissociável (Abib, 1994) com a cultura que o define, produzindo aquilo tradicionalmente chamado de "linguagem". Do mesmo modo que o comportamento que a produz, a linguagem é, portanto, um fenômeno dependente da cultura e da história e se caracteriza pela diversidade de interesses específicos de grupos com práticas sociais diversificadas (Skinner, 1957). Esses grupos mantêm suas práticas com uma linguagem que descreve classes de comportamentos, conseqüências e antecedentes a certos comportamentos, e reforçam a sua emissão em contextos específicos.

Como relação, o operante verbal é a própria ação do falante (e não a expressão de uma idéia mental ou de uma representação) em interação com ouvintes, falando, escrevendo, gestualizando a partir do controle de estímulos (coisas, acontecimentos, eventos, palavras faladas, lidas ou ouvidas, outras pessoas ou propriedades desses "objetos" ou pessoas) e consequiências providas por ouvintes dessa interação. Isso inclui uma interação social verbal naquilo que Skinner chamou de episódio verbal. Discurso é um conjunto de operantes verbais com certas propriedades (encadeamento, intensidade, etc.). Por isso, parafraseando Dijk (2004), uma vez que o discurso é uma abstração (pois ele só existe a partir do conjunto de comportamentos verbais que o define), é melhor que o analista (do comportamento) se concentre nesses comportamentos; ou nas propriedades do conjunto, uma vez que a abstração que constitui o discurso é um fenômeno "tipicamente verbal" (Borloti, 2005; Skinner, 1957). Ao conjunto chamaremos discurso.

Em síntese, as seguintes proposições skinnerianas acerca do comportamento verbal fundamentam a ACD:

\section{Pressupostos da ACD}

Alguns elementos básicos da ACD são caracterizados pela abordagem behaviorista radical da linguagem, conforme sintetizadas por Owen (2003, p. 20): monismo: "tudo aquilo que fazemos ou dizemos é comportamento. A atividade simbólica é uma forma especializada de comportamento social"; contextualismo: "o significado de um evento envolvendo linguagem é descoberto ao se identificar as contingências naturais elou sociais que ocasionam o seu uso. As palavras referem as pessoas às coisas. Elas 'acomodam' as coisas de modo relacional"; definições funcionais da linguagem: "os eventos abertos/encobertos diretamente observáveis são definidos em termos de sua relatividade funcional a outros eventos em um contexto específico. Fala é arranjo relacional'.

As outras marcas permanentes do behaviorismo radical para a análise do comportamento em geral (Chiesa, 1994; 
Micheletto, 1997) também caracterizam a ACD: o discurso é o interesse do analista comportamental na ACD, 2) o discurso é determinado por contingências (passadas e atuais), 3) o discurso é um dado empírico e 4) sua análise afasta-se da metafísica. Portanto, 5) a ACD é um procedimento de uma ciência natural que se propõe a prever e a controlar o discurso. Tendo essas marcas, um experimento antigo de Verplanck (1955) mostrou como o conteúdo de conversas pode ser manipulado.

Kohlenberg e Tsai (1991/2001) propuseram uma síntese dos três princípios que sustentam uma ACD: 1) a natureza contextual e histórica do conhecimento e da "realidade" que controlam o discurso, 2) a visão anti-mentalista do discurso, com enfoque nas variáveis ambientais que o controlam e 3) o foco nos comportamentos que se juntam formando um discurso. Adotar esses princípios é, em primeiro lugar, identificar uma base construtivista ou contextualista na ACD que prioriza a análise da história como a chave para a compreensão do discurso que se desenrola. Isto é, objetivamente, enfatizar as relações de controle que caracterizam o contexto ambiental (e que dão o significado ao discurso) num dado momento. Parafraseando Kohlenberg e Tsai, "tire o discurso do seu contexto e ele perderá seu significado. Ponha o discurso em um novo contexto e ele significará outra coisa" (Kohlenberg \& Tsai,1991/2001, p. 4).

Em segundo lugar, é compreender o discurso como uma descrição de relações funcionais entre eventos (incluindo, por exemplo, comportamentos). Fazer ACD é, portanto, fazer análise funcional dessa descrição, ou seja, descobrir sua função.

Isso dá pistas para o que vem em terceiro lugar: o discurso tem sua origem no ambiente e no modo como esse ambiente é manipulado. Assim, entender o significado do discurso é conhecer quais relações controlam o falar e, por extensão, o pensar ou o escrever algo (Day, 1969b). Gergen (1985) apresentou algo semelhante ao listar os pressupostos do construcionismo social: os termos de um discurso são "artefatos históricos" produzidos na mediação entre as pessoas, caracterizada por negociações, conflitos, retórica, etc., cujos significados derivam do seu contexto de emissão.

As linguagens - as práticas verbais de uma comunidade sob controle das condições que dão a elas um significado - requerem uma cultura verbal, definida por Skinner (1971) como comportamentos de falantes e ouvintes, ou artefatos produzidos por eles (por exemplo, artigos e livros). "Para explicá-los, precisamos recorrer às contingências que os produzem" (p. 127), já que cultura (assim como linguagem ou discurso) é uma abstração. A mediação verbal entre as pessoas de uma cultura define um episódio verbal, um momento no qual condições culturais impelem um ouvinte a reforçar o comportamento de um falante compondo as interações sociais verbais:

\footnotetext{
(...) o comportamento verbal é modelado e mantido por um meio verbal - por pessoas que respondem de certa maneira ao comportamento por causa das práticas do grupo do qual são membros. Essas práticas e a interação resultante entre o falante e o ouvinte produzem os fenômenos considerados sob a rubrica de comportamento verbal (Skinner, 1957, p. 226).
}

Sob tal rubrica estão muitos repertórios humanos (a fala, a compreensão, a leitura, a escrita, os gestos, sinais de fumaça, a arte, a música, as autofalas, o pensamento verbal, a imaginação e quaisquer outros comportamentos mediados por outra pessoa, ou pelo próprio falante), mesmo quando a mediação é impessoal e difusa, como ocorre na interação com a mídia (Guerin, 1992). O que importa sempre é a função da linguagem e isso caracteriza o pragmatismo como um fundamento da $\mathrm{ACD}$, o mesmo fundamento das abordagens sócio-contextuais da comunicação humana (Owen, 2003). Ao mesmo tempo, a ACD se destaca devido a um interesse na natureza comportamental-contextual da linguagem (Day, 1969a; Moore, 1991; Owen, 1993) que prioriza a identificação dos processos que a produzem: as práticas reforçadoras passadas e atuais de uma comunidade social-lingüística. Tais práticas atuam sobre o discurso de seus membros, mantêm e promovem essas mesmas interações ao atuar como regra, descrevendo as classes de estímulos antecedentes e de consequentes que as mantém.

Práticas sociais também incluem o modo como a comunidade verbal reforça formas de ações verbais que se tornam regras por serem efetivas em certas circunstâncias. Partindo-se de sua descrição (o que é dito, escrito, etc.) avança-se para a sua análise funcional (quando e por que é dito, escrito, etc.) de modo a explicar as propriedades dinâmicas dos episódios verbais envolvendo o discurso. A análise funcional está, dessa forma, além da descrição de uma conexão. "Os estímulos que controlam uma resposta verbal não apenas determinam sua forma, fornecendo assim um equivalente para o sentido, mas também aumentam a probabilidade de que a resposta seja emitida" (Skinner, 1957, p. 199, grifos acrescido pelos autores). A análise desse contexto de estímulo permite entender a combinação de variáveis atuando sobre o discurso. É assim que o significado do discurso não é uma propriedade do comportamento per se, mas das condições (históricas e atuais) sob as quais ele ocorre. Assim, o contexto de uma interação em um episódio verbal fornece os significados aos eventos, objetos, acontecimentos do mundo, ou às propriedades destes. Por contexto entendem-se as circunstâncias sob as quais "o mundo" tem seu efeito sobre o falante. Ele determina o significado do que é dito, escrito ou gestualizado. "Mundo" inclui coisas vivas (por exemplo, ouvintes) e inanimadas, atividades, relações entre estímulos (verbais ou não) ou quaisquer de suas propriedades (Catania, 1998), contactadas no presente a partir da experiência passada no contato com elas. Assim, o significado não está nas palavras ou no dicionário da língua; não está inserido no falante ou no ouvinte; também não está na situação atual. O significado está na história de exposição do falante a ambientes semelhantes nos quais certas contingências desempenharam um papel seletivo (Skinner, 1957). Abib (1994) pôs essa questão nestes termos:

(...) uma resposta verbal a uma situação não é o significado, e
tampouco é a própria situação; então, uma resposta verbal a uma
situação é uma relação que significa uma outra relação (...). As-
sim, uma relação atual entre uma resposta verbal e uma situação
significa uma outra relação que é a história de contingências de
reforçamento, isto é, o significado - responsável pela instanciação
daquela relação no presente. Nesse sentido, o comportamento
verbalé sempre significativo e é sempre explicado por significados
- mesmo que desvelá-los não seja tarefa simples (p. 485).

O ouvinte infere o significado do discurso (ou seja, as suas variáveis controladoras), observando (ficando sob controle discriminativo) as circunstâncias sob as quais o 
discurso ocorre; toma em consideração o que ele sabe sobre o falante e sobre tais circunstâncias. O falante, por sua vez, indica - de modo óbvio ou não - as variáveis sob as quais fala, na tentativa de gerar compreensão ou crença no ouvinte (Guerin, 1994; Skinner, 1957). O comportamento do ouvinte depende, obviamente, da sua história de vida e das condições dessa história: pessoas que lhe são interessantes, que falam o que ele gosta de ouvir, que supostamente sabem, e assim por diante. É com essas variáveis que o comportamento do ouvinte pode ser manipulado pelo comportamento do falante, já que o discurso é emitido na interação com outras pessoas, a partir do controle de estímulos em um episódio verbal. Esse controle inclui as condições antecedentes e conseqüentes ao comportamento, e essas últimas são, fundamentalmente, as conseqüências sobre ouvintes e falantes, incluindo o reforço generalizado que mantém o encadeamento da fala, uma das propriedades verbais que define o discurso. Ao "adotar" o discurso do falante, o ouvinte pode estar sob controle apenas da descrição ou, num controle mais estrito do ambiente, da descrição e das circunstâncias descritas.

O reforço generalizado é a chave do sucesso dos discursos práticos e científicos. Ele coloca o comportamento do falante mais estreitamente sob o controle do meio ambiente e permite que o ouvinte reaja a esse comportamento com mais sucesso em lugar de um contato direto com o meio (Skinner, 1957, p. 182).

"Mais sucesso" pode ser explicado assim: uma vez que as ações verbais começam a ter efeitos sobre o mundo pelo comportamento do ouvinte, elas passam a depender do "mundo das palavras" e podem, por essa razão, desvincular-se do "mundo das coisas". Assim desvinculadas, agem como estímulos em sequiências de "verbalizações", independentes de suas relações com o mundo "real" acerca delas. É assim que o comportamento verbal "constrói" uma realidade sob controle de certas circunstâncias (Guerin, 1992; Skinner, 1957).

Ao analisar um discurso, conjetura-se um conjunto plausível dessas circunstâncias e, principalmente, se lida com o próprio comportamento de responder a ele (Skinner, 1957). Dessa forma, o analista (comportamental) do discurso estuda os efeitos que os registros do discurso têm sobre o seu próprio comportamento verbal (como ouvinte ou leitor). É de tais efeitos - e sob controle de outros documentos ou informações - que se pode inferir "a história de uma forma particular de resposta e de todas as variáveis que adquiriram controle sobre ela" (Skinner, 1957. p. 189). Essas inferências são feitas observando-se, nas comunidades verbais atuais, as mudanças nas contingências de reforço; e essas "podem ser traçadas historicamente" (p. 469). Nesse trabalho, não se pode esquecer que "partes diferentes de uma comunidade verbal, ou da mesma comunidade em ocasiões diferentes, podem reforçar respostas diferentes" (p. 227), desvelando o que se poderia chamar de dinamicidade ou polissemia do discurso.

Assim, o sentido do discurso advém das contingências que controlam as relações entre o comportamento verbal e objetos ou acontecimentos (ou propriedades objetos ou acontecimentos) que podem ou não ter sido tateados pelo falante. A negociação de argumentos parece levar o ouvinte a ver algo à maneira do falante $\mathrm{e}$, ao fazer isso, o falante combina operantes essenciais, formando grupos temáticos em falas continuadas (o que Skinner chamaria de intraverbais) como se estivessem sob controle das coisas ou acontecimentos (ou suas propriedades) e garante a eficácia do discurso com estratégias estilísticas (o que Skinner chamaria de autoclíticos). Guerin (1998) fez uma análise de como membros de uma religião controlam comportamentos dessa maneira.

Da argumentação de Skinner (1957) e Guerin (1992, 1994), é possível definir funcionalmente os operantes verbais de um discurso: os mandos são basicamente os repertórios analisados pelos analistas do discurso da vertente dos Atos de Fala (desculpas, juramentos, advertências, súplicas, etc.), pois especificam um reforçador cujo valor potencial é definido por uma operação estabelecedora de privação (do perdão de alguém, por exemplo) ou de estimulação aversiva (um movimento grevista, por exemplo). O discurso é reforçado pela obtenção desse reforçador (o fim da greve, por exemplo) e essa contingência explica a manutenção do discurso. Os tatos são relações que resultam da discriminação de estímulos nãoverbais ou de suas propriedades. Esses estímulos poderiam ser os "objetos" do discurso: a homossexualidade, a reforma agrária, a violência, a justiça, a doença mental, etc. Os intraverbais são relações arbitrárias entre respostas verbais e os estímulos verbais que as ocasionam. A vertente da Pragmática na análise de conversações (Antaki \& Díaz, 2004) ilustra o foco sobre operantes intraverbais, ou seja, sobre como a fala de um, ou a fala do próprio falante, controla a fala de outro ou a sua própria, em conversas. Por fim, os autoclíticos são os processos envolvidos no "estilo verbal", aquilo que interessa aos estudiosos da Retórica. Eles são relações verbais que emergem da discriminação de relações entre outros operantes, dos quais depende a sua ocorrência. Eles modificam os efeitos dos demais operantes sobre o ouvinte, quando descrevem, quantificam, qualificam, relacionam ou compõem o que é falado, escrito ou "dito" de outro modo (Borloti, 2004b).

\section{Como fazer ACD}

O início de um procedimento de ACD pode ser inferido do texto de Skinner (1957): tendo registrado os sons da fala em uma interação ou entrevista, 1) transcreva as respostas verbais (criando diferentes notações para ênfases, pausas, etc.), 2) isole os segmentos de comportamentos verbais de interesse (por exemplo, argumentos de defesa ou de crítica de um "objeto" qualquer), e 3 ) infira seus operantes essenciais e elos temáticos intraverbais surgidos do encadeamento desses operantes essenciais e, por fim, a estrutura autoclítica principal que envolve esses operantes. (É possível obter discursos já transcritos em cartas, manifesto ou outra forma de texto).

A premissa básica da ACD encontra-se no texto de Skinner (1957, p. 452): "quando estudamos [discursos], estudamos os efeitos [dos discursos] sobre nós. É o nosso comportamento em relação a tais [discursos] o que nós observamos". Borloti (2004b) descreveu como essa tarefa pode ser simplificada, reservando atenção às funções do processo autoclítico: a ACD é o resultado da discriminação das variáveis que controlaram o comportamento do analista em contato com o registro do discurso.

É importante ler o registro modulando a intensidade, a energia e a velocidade da leitura para que se possa inferir, desses 
indicadores de força, um conjunto plausível de condições determinantes. Esses indicadores de força podem ser checados ao se ouvir ou assistir ao registro auditivo ou visual do dado verbal e ao discutir suas discriminações com outros leitores ou ouvintes (Borloti, 2004b, p. 229).

Esse procedimento inicial, sugerido por Skinner (1957), foi complementado no final da década de 1970 pela equipe do professor Willard Day, da Universidade de Nevada, configurando o que veio a ser denominado Reno Method (Moore, 1991). A equipe articulou-o com um movimento filosófico forte naquela época: a hermenêutica, "a arte e a ciência da interpretação" (Runes, 1985).

Ao que parece, Gadamer (1997) é o representante da hermenêutica a qual o método da ACD se vincularia diretamente por enfatizar a superação da dicotomia sujeito-objeto na compreensão do discurso. Dessa forma, o significado de um registro verbal qualquer é obtido por meio de um processo de aproximação gradual ao registro como o produto de práticas de uma comunidade verbal. Nessa aproximação, sondam-se todas as propriedades do registro e, se puder, de outros registros a ele relacionados para, então, com a compreensão assim gerada, voltar ao registro original para clarificar e esclarecer uma interpretação que foi possível. Na prática da ACD, isso significa que o analista faz questões propostas por certas propriedades do registro a si mesmo. Como diria Gadamer (1997), a ACD é a verdadeira "dialética de perguntas e respostas" que caracteriza a interpretação analítico-comportamental do discurso. Por exemplo: "Como o falante me parece aqui?", "Acho que ele está sendo irônico/presunçoso/etc.", "Por que será que sinto isto?". Perguntas são necessárias e persistentes até a obtenção de uma interpretação satisfatória. Esse caminhar analítico deverá ser descrito de modo que a interpretação possa ser corroborada na interpretação de outros analistas. Stein (2002) pontua que essa interpretação hermenêutica é contextual: a interpretação do registro verbal é uma compreensão progressiva, que é, de fato, uma autocompreensão do comportamento do intérprete. Day (citado por McCorkle, 1990/1991) foi afetado por essa forma de interpretar e deixou bem claro que a influência maior para o que ele denominou de Hermenêutica Comportamental adveio do behaviorismo de Skinner:

Ao tomar as realidades do discurso efetivo comum como a base para a verdade e a certeza epistemológica, a abordagem hermenêutica não poderia separar o domínio de significado dado pela experiência do domínio do assunto e, assim, não procederia a analisar esses domínios em termos de unidades analíticas que são tomadas como sendo reais. Dessa forma, a experiência de mundo das pessoas não seria vista a priori como composta por idéias, pensamentos, sensações, percepções, imagens e assim por diante, as quais podem ser consideradas como entidades reais independentes das práticas sociais que nos capacitam a falar e pensar sobre elas. A experiência de mundo das pessoas é conhecida pela análise do que elas têm a dizer sobre as coisas, e o que as pessoas têm a dizer é tomado, então, como objeto de análise, no sentido de ser um 'texto'. E mais: ainda que eu queira associar meu próprio tipo de pensamento em alguma extensão com a hermenêutica, particularmente com a sua oposição às estratégias de redução epistemológica, não tenho dúvida de que meu pensamento tem sua fonte muito mais fundamentada no behaviorismo radical de B. F. Skinner. (Daycitado por McCorkle, 1990/1991, sem página).

McCorkle (citado por McCorkle, 1990/1991) sintetizou os desmembramentos pragmáticos desse tipo de compreensão do conhecimento. Tais desmembramentos devem ser considerados no uso de uma ACD:

1) qualquer material verbal sob análise foi produzido por comportamentos emitidos com a função de modelar um comportamento verbal discriminativo no repertório do leitor/analista e influenciar seu comportamento verbal subsequiente de forma a induzi-lo a funcionar dentro de um discurso coerente;

2) o objetivo básico de um estudo usando a ACD é colocar o analista do discurso diante do registro do comportamento de interesse (argumentos favoráveis, modos de descrição, formas de convencimento, indução de culpa, etc.), de modo a observá-lo diretamente;

3) ouvir diretamente a gravação do comportamento verbal ou ler seu registro (a transcrição ou um documento primário escrito) várias vezes tem função adaptativa, pois a repetição força o contato do analista com novos estímulos ou propriedades desses que controlam discriminações novas e relevantes em seu repertório verbal atual;

4) tendo adquirido esses repertórios discriminativos novos como resultado da observação direta do comportamento de interesse, o analista do discurso deve fazer a análise, ou seja, responder verbalmente sob controle do que observou e sob controle de outras fontes verbais (outros documentos primários ou secundários);

5) o modo de pesquisar e conceituar fenômenos em Análise do Comportamento invariavelmente conduz o analista do discurso a: a) dar um sentido anti-mentalista ao comportamento observado; e b) focar-se no "como" as variáveis ambientais agem (e agiram) para controlar o comportamento;

6) o foco primário da atenção do analista é sobre o seu comportamento ao conduzir os passos da análise, já que a ACD é uma forma de autodescrição do comportamento de analisar e das circunstâncias ambientais que atuaram na análise.

Essas implicações também podem configurar um matiz comportamental aos métodos historiográficos já que esses são basicamente empregados na análise do produto do comportamento verbal em documentos primários ou secundários (Parrot \& Hake, 1984).

McCorkle (1990/1991) vai mais além nas recomendações ao pesquisador: o analista comportamental do discurso deve, ao relatar sua pesquisa, descrever o que fez verbalmente ao analisar: o que trouxe de arcabouço conceitual para a análise, que a análise controla os comportamentos de seus leitores ou qualquer outra informação concernente ao contexto do seu trabalho verbal (um exemplo desse tipo de relato pode ser visto em Borloti, 2003, que, sob controle do texto do livro O Comportamento Verbal e de outros documentos primários e secundários, definiu e descreveu seu comportamento de inferir os controles sobre o comportamento verbal de Skinner ao escrever o livro).

Objetivando facilitar a tarefa, Dougher (1993) descreveu de modo instrucional as quatro etapas da condução da Hermenêutica Comportamental: 1) ouça e leia várias vezes o registro verbal, buscando ocorrências do comportamento de 
seu interesse e dos eventos antecedentes que parecem estar funcionalmente relacionados a ele; 2) reveja o dado para encontrar exemplos que confirmem a regularidade dessas relações; 3 ) faça uma outra descrição funcional, só que do seu próprio comportamento ao conduzir o passo anterior, refinando as discriminações feitas e agrupando os comportamentos de interesse em classes que compartilham funções comuns; 4) descreva o seu comportamento de inferir, de modo a discriminar verbalmente quais amostras você selecionou e por que. Nessa tarefa desconstrucionista das relações verbais registradas é que emerge a análise comportamental do discurso. No caso de relações verbais que geram um texto como produto

(...) é presumido que o leitor compreenderá somente na medida em que fica sob controle do que impeliu o escritor a escrever. Ao desconstruir um texto, o leitor compreende seu significado somente quando compreende os controles sobre seu próprio comportamento como leitor e no ponto no qual esses controles se sobrepõem àqueles do escritor. A distinção entre 'leitor' $e$ 'escritor' é, no ponto em que os controles se interseccionam, uma distinção artificial baseada na localidade, que ignora a função comportamental. O leitor é um escritor (isto é, ele se comporta do mesmo modo, embora a mecânica do movimento possa não ter nenhuma similaridade) na medida em que as variáveis atuando sobre seu comportamento se sobrepõem às variáveis controladoras do comportamento do escritor. Então, cada ato de leitura é, por extensão, um ato de escrita; cada ato de escuta é um ato de fala (Vargas, 1992, p. xxiii).

\section{Conclusões}

Uma ACD pode ser considerada um exercício interpretativo da função de um conjunto de operantes verbais (o discurso). Os fundamentos de uma ACD permitem entender tanto a variação quanto a permanência do conjunto; a que tipo de audiência interessa variar ou permanecer. O método de ACD apresentado aqui é uma maneira de descrever o modo como o discurso, geralmente sob a forma de texto (um produto verbal), atua no controle de estímulo (antecedente e conseqüente) para o comportamento de interpretá-lo a partir de uma função possível. Nesse exercício, é importante lembrar do controle múltiplo atuando sobre operantes de um discurso, e que é mais evidente quando se foca o uso que o falante faz de certos recursos estilísticos. Por exemplo:

A resposta Acredite-me, é verdade contém um mando e um tato. A função do mando em coagir o ouvinte a reagir 'com maior crédito' ao tato pode ser exercitada mediante uma forma mais urgente de tato (É VERDADE!) que deve ser atribuída a múltiplas fontes (Skinner, 1957, p. 234, na qual o autor sugere uma forma de registrar ênfase ao indicar com letras maiúsculas a "forma mais urgente" - ou a força - de emissão do operante exemplificado).

A análise da função do discurso pelo procedimento aqui descrito permite inferir a reação do ouvinte/leitor ao discurso a partir dos processos que aumentariam a probabilidade de um discurso vir a ocorrer num futuro, no repertório do falante e/ou do ouvinte. A classe de comportamentos "obediência" ou "simpatia" à causa de um movimento social poderiam ser exemplos de eficácia de um discurso (por exemplo, comenta- ristas políticos dizem que o presidente Lula foi reeleito "usando" o mesmo "discurso da continuidade" do seu antecessor, Fernando H. Cardoso). Assim, a ACD pode ser empregada na análise de propriedades de discursos bem-sucedidos para verificar se elas se repetem em outros discursos assim classificados. As vantagens e desvantagens do método aqui descrito dizem respeito à extensão na qual a interpretação é a possibilidade de análise. $\mathrm{O}$ método apresentado descreve uma forma de fazê-la.

Em resumo, a abordagem aqui é de aproximação às Ciências Sociais. Ela aponta os fundamentos de uma ACD para a investigação de problemas que interessam aos pesquisadores sociais pelo matiz diferenciado do behaviorismo radical. O termo "discurso" é apenas uma conveniência a essa aproximação, já que, em sua análise, se empregam as mesmas definições validadas pela Análise Experimental do Comportamento que apontam para a função de operantes verbais emitidos em conjunto a partir de certas circunstâncias. Se tais circunstâncias foram operações estabelecedoras (a falta de um posto de saúde, por exemplo), isso alteraria a probabilidade de ocorrência de mandos no repertório de falantes que liderariam as "bases" de um movimento social em uma comunidade (Borloti, 2004a). Se há semelhanças entre circunstâncias atuais e passadas nas quais o provérbio "Não troque o certo pelo duvidoso" tenha sido reforçado, isso aumenta a probabilidade da reemissão desses intraverbais (mesmo quando emitidos como se fossem tatos).

\section{Referências}

Abib, J. A. D. (1994). O contextualismo do comportamento verbal: A teoria skinneriana do significado e sua crítica ao conceito de referência. Psicologia: Teoria e Pesquisa, 10(3), 473-487.

Andresen, J. T. (1990). Skinner and Chomsky thirty years later. Historiographia Linguistica, 17(1/2), 145-165.

Antaki, C. \& Díaz, F. (2004). A análise da conversação e o estudo da interação social. Em L. Iñiguez (Org.), Manual de análise do discurso em Ciências Sociais (V. L. Joscelyne, Trad.) (pp. 161-180). Petrópolis: Vozes.

Austin, J. L. (1998). Cómo hacer cosas con palabras. Barcelona: Paidós.

Banchs, M. (1988). Cognición social y representación social. Revista de Psicología de El Salvador, 7(30), 361-372.

Bardin, L. (1979). Análise de conteúdo. Lisboa: Ed. 70/Persona.

Bauer, M. W. \& Gaskell, G. (Orgs.). (2002). Pesquisa qualitativa com texto, imageme som: Um manual prático (P. A. Guareschi, Trad.). Petrópolis: Vozes. (Trabalho original publicado em 2000)

Baum, W. M. (1999). Compreender o behaviorismo: Ciência, comportamento e cultura (M. T. A. Silva, M. A. Matos, G. Y. Tomanari \& E. Z. Tourinho, Trads.). Porto Alegre: ArtMed. (Trabalho original publicado em 1994)

Billig, M. (1987). Arguing and thinking: A rhetorical approach to Social Psychology. Cambridge: Cambridge University Press.

Borloti, E. B. (2005). Abstração, metáfora, sonho e inconsciente: Uma interpretação skinneriana. Em E. B. Borloti, S. R. F. Enumo \& M. P. L. Ribeiro (Orgs.), Análise do Comportamento: Teorias e práticas (pp. 69-96). Santo André: ESETec.

Borloti, E. B. (2004a) Comportamento verbal em movimentos sociais: Estratégias de inclusão. Em L. de Souza \& Z. A. Trindade (Orgs.), Violência e exclusão: Convivendo com paradoxos (pp. 176-194.). São Paulo: Casa do Psicólogo. 
Borloti, E. (2004b). As relações verbais elementares e o processo autoclítico. Revista Brasileira de Terapia Comportamental e Cognitiva, 6(2), 221-236.

Borloti, E. (2003). O discurso de Skinner: uma análise funcional do citar no Verbal Behavior. Tese de Doutorado, Pontifícia Universidade Católica de São Paulo, São Paulo.

Borloti, E. B. \& Trindade, Z. A. (2000). A análise do comportamento e as proposições da construção social do conhecimento. Estudos de Psicologia, 17(2), 41-51.

Catania, A. C. (1998). The taxonomy of verbal behavior. Em K. A. Lattal \& M. Perone (Orgs.), Handbook of research methods in human operant behavior (pp. 405-433). New York: Plenum.

Chiesa, M. (1994). Radical behaviorism: the philosophy and the science. Boston: Authors Cooperative: Inc. Publishers.

Day, W. F. (1969a). On certain similarities between the philosophical investigations of Ludwig Wittgenstein and the operationism of B. F. Skinner. Journal of the Experimental Analysis of Behavior, 12(3), 489-506.

Day, W. F. (1969b). Radical behaviorism in reconciliation with phenomenology. Journal of the Experimental Analysis of Behavior, 12(2), 315-328

Dijk, T. A. (2004). O giro discursivo. Em L. Iñiguez, L. (Org.), Manual de análise do discurso em Ciências Sociais (V. L. Joscelyne, Trad.) (pp. 7-14). Petrópolis: Vozes.

Dougher, M. J. (1993). Interpretative and hermeneutic research methods in the contextualistic analysis of verbal behavior. Em S. C. Hayes, L. J. Hayes, H. W. Reese \& T. S. Sarbin (Orgs.), The varieties of scientific contextualism (pp. 147-159). Reno: Context Press.

Gadamer, H. G. (1997). Verdade e método: Traços fundamentais de uma hermenêutica filosófica (F. P. Meurer, Trad.). Petrópolis: Vozes.

Gergen, K. J. (1985). The social constructionist movement in modern psychology. American Psychologist, 40(3), 266-75.

Gill, R. (2002). Análise de discurso. Em M. W. Bauer \& G. Gaskell (Orgs.), Pesquisa qualitativa com texto, imagem e som: Um manual prático (P. A. Guareschi, Trad.) (pp. 244-270). Petrópolis: Vozes. (Trabalho original publicado em 2000)

Gracia, T. I. (2004). O "giro lingüístico". Em L. Iñiguez (Org.), Manual de análise do discurso em Ciências Sociais (V. L. Joscelyne, Trad.) (pp. 19-49). Petrópolis: Vozes.

Guerin, B. (1998). Religious behaviors as strategies for organizing groups of people: A social contingency analysis. The Behavior Analyst, 21(1), 53-72.

Guerin, B. (1994). Attitudes and beliefs as verbal behavior. The Behavior Analyst, 17(1), 155-163.

Guerin, B. (1992). Behavior Analysis and the social construction of knowledge. American Psychologist, 47(11), 1423-1432.

Iñiguez, L. \& Antaki, C. (1994). El análisis del discurso en Psicología Social. Boletín de Psicología, 44, 57-75.

Iñiguez, L. (Org.) (2004a). Manual de análise do discurso em Ciências Sociais (V. L. Joscelyne, Trad.). Petrópolis: Vozes.

Iñiguez, L. (2004b). Os fundamentos da análise do discurso. Em L. Iñiguez (Org.), Manual de análise do discurso em Ciências Sociais (V. L. Joscelyne, Trad.) (pp. 50-104). Petrópolis: Vozes.

Iñiguez, L. (2004c). Prática da análise do discurso. Em L. Iñiguez (Org.), Manual de análise do discurso em Ciências Sociais (V. L. Joscelyne, Trad.) (pp. 105-160). Petrópolis: Vozes.

Kohlenberg, J. R. \& Tsai, M. (2001). Psicoterapia analítica funcional: Criando relações terapêuticas intensas e curativas (F. Conte, M. Delitti, M. Z. S. Brandão, P. R Derdyk, R. R. Kerbauy, R. C.
Wielenska, R. A. Banaco \& R. Starling, Trads.). Santo André: ESETec. (Trabalho original publicado em 1991)

Lamal, P. A. (1991). Behavior Analysis of societies and cultural practices. New York: Hemisphere.

Lane, S. T. M. (1995). Avanços da psicologia social na América Latina. Em S. T. M. Lane \& B. B. Sawaia (Orgs.), Novas veredas da Psicologia Social (pp. 67-81). São Paulo: Brasiliense/Educ.

Levinson, S. C. (1983). Pragmatics. Cambridge: Cambridge University.

McCorkle, M. (1990/1991). A retrospective account of some qualitative research. The Qualitative Report, 1 (2 and 3). Retirado em 10/04/2006 do http://www.nova.edu/ssss/QR/QR1-23/mccorkle.html

McNeill, D. (1985). So do you think gestures are non-verbal? Psychological Review, 92(3), 350-371.

Micheletto, N. (1997). Bases filosóficas do behaviorismo radical. Em R. A. Banaco (Org.), Sobre comportamento e cognição, vol.1 (pp. 29-44). Santo André: ESETec.

Moore, J. (1991). A retrospective appreciation of Willard Day's contributions to radical behaviorism and the analysis of verbal behavior. The Analysis of Verbal Behavior, 9(1), 97-104.

Owen, J. L. (1993). On contextual interpretations of behavior. Em S. C. Hayes, L. J. Hayes, H. W. Reese \& T. S. Sarbin (Orgs.), The varieties of scientific contextualism (pp. 222-225). Reno: Context Press.

Owen, J. L. (2003). A retrospective on behavioral approaches to human language: And some promising new developments. American Communication Journal, 5(3). Retirado em 10/04/06 do http://www.acjournal.org/holdings/vol5/iss3/articles/owen.pdf

Parker, I. (1999). Varieties of discourse and analysis. Em I. Parker \& The Bolton Discourse Network (Orgs.), Critical textwork: An introduction to varieties of discourse and analysis (pp. 1-13). Buckingham: Open University Press.

Parker, I. (1992). Discourse dynamics: Critical analysis for social and individual psychology. London: Routledge.

Parrot, L. J. \& Hake, D. F. (1984). Toward a science of history. The Behavior Analyst, 6(2), 121-132.

Pereira, M. E. M. (2000). O estudo da linguagem pela psicologia: Uma aproximação entre Skinner e Bakhtin. São Paulo: Educ.

Perelman, C. H. (1993). O império retórico. Porto: Edições ASA.

Potter, J., Wetherell, M., Gill, R. \& Edwards, D. (1990). Discourse: Noun, verb or social practice? Philosophical Psychology, 3(2), 205-217.

Richelle, M. (1976). Formal analysis and functional analysis of verbal behavior: Notes on the debate between Chomsky and Skinner. Behaviorism, 4(2), 209-221.

Rocha-Coutinho, M. L. (1998). A análise do discurso em Psicologia: Algumas questões, problemas e limites. Em L. de Souza, M. de F. Q. de Fretas \& M. M. P. Rodrigues (Orgs.), Psicologia: Reflexões (im)pertinentes (pp. 317-345). São Paulo: Casa do Psicólogo.

Runes, D. D. (Org.) (1985). Diccionario de Filosofía. Barcelona: Grijalbo.

Sá, C. P. de. (1994). Sur les relations entre representations sociales, pratiques socio culturelles et comportament. Papers of social representations, 3(1), 40-46.

Sá, C. P. de (1983). Sobre o poder em Foucault e o controle em Skinner. Arquivos Brasileiros de Psicologia, 35(2), 136-145.

Searle, J. R. (1965). ¿Qué es un acto de habla? Valencia: Revista Teorema. Retirado em 10/04/06 do http://www.upv.es/sma/teoria/ sma/speech/Que\%20es\%20un\%20acto\%20de\%20habla.pdf

Skinner, B. F. (1971). Beyond Freedom and Dignity. New York: Alfred A. Knopf. 
Skinner, B. F. (1986). The evolution of verbal behavior. Journal of the Experimental Analysis of Behavior, 41(1), 217-222.

Skinner, B. F. (1957). Verbal Behavior. New York: AppletonCentury, Crofts.

Spink, M. J. P. \& Frezza, R. M. (1999). Práticas discursivas e produção de sentidos: A perspectiva da Psicologia Social. Em M. J. Spink (Org.), Práticas discursivas e produção de sentidos no cotidiano: Aproximações teóricas e metodológicas (pp. 17-39). São Paulo: Cortez.

Stein, E. (2002). A consciência da História: Gadamer e a hermenêutica. Folha de São Paulo, Caderno Mais. Recutirado em 10/04/06 do http://www.cfh.ufsc.br/ wfil/gadamer.htm

Terrell, D. \& Johnston, J. M. (1989). Logic, Reasoning, and verbal behavior. The Behavior Analyst, 12(1), 35-44.

Vargas, E. A. (1992). Introduction II. Em B. F Skinner (Org.), Verbal behavior (pp. xiii-xxv). Acton: B. F. Skinner Foundation, Copley Publishing Group.
Vargas, E. A. (1991). Verbal behavior: A four-term contingency relation. Em W. Ishaq (Org.), Human Behavior in Today's World (pp. 99-108). New York: Praeger.

Verplanck, W. S. (1955). The control of the content of conversation: Reinforcement of statements of opinion. Journal of Abnormal Social Psychology, 51(3), 668-676.

Woodward, W. R. (1996). Skinner and behaviorism as cultural icons: From local knowledge to reader reception. Em L. D. Smith \& W. R. Woodward (Orgs.), Skinner and behaviorism in American culture (pp. 7-34). Bethlehem: Lehigh University Press.

Recebido em 15.05.2006

Primeira decisão editorial em 18.09.2006

Versão final em 07.11.2006

Aceito em 22.02.2007 